\title{
Editorial: Rendezvous With Truth and Discovery
}

\section{Mark A. Mattaini ${ }^{1}$ (D) Ruth Anne Rehfeldt ${ }^{2}$}

Published online: 27 July 2020

(C) Association for Behavior Analysis International 2020

The police violence pandemic directed toward members of racialized populations in the United States, particularly but not exclusively African American men (African American women and indigenous groups face similar injustices), has produced widespread protests and some immediate changes across the United States and around the world. The extent to which the Black Lives Matter movement will be sustained as was the civil rights movement in the 1960s is not yet known, but broad participation among racial, economic, and age groups is encouraging. There are opportunities for all to participate in the movement simply as members of society; we argue here, however, that behavior scientists and practitioners have unique potential, and an ethical obligation, to contribute to achieving meaningful change while recognizing that we offer only part of what is necessary for social advancement.

In 1967, Reverend Martin Luther King, Jr. (1968), gave a distinguished address to the American Psychological Association titled "The Role of the Behavioral Scientist in the Civil Rights Movement." He noted that "for social scientists, the opportunity to serve in a life-giving purpose is a humanist challenge of rare distinction. Negroes too are eager for a rendezvous with truth and discovery." He then suggested areas where help would be welcomed. The need is clearly still great, but behavior science has yet to prioritize this work. Perhaps this is the moment. The Association for Contextual Behavioral Science recently released a statement reading, in part,

We, the Board of ACBS, are writing this statement to unequivocally oppose structural, cultural, and individual racism, racially motivated violence, hate speech and all forms of prejudice and oppression in evidence throughout the world. We invite our community of researchers, therapists, and helpers to look hard at the many ways in which racism manifests in the world at large. We ask that our scientific community bring to bear the significant strength of contextual behavioral science in shining a light and exploring solutions to discrimination and

Mark A. Mattaini

mattaini@uic.edu

1 Jane Addams College of Social Work, University of Illinois at Chicago, PO Box 1045, Paguate, NM 87040, USA

2 The Chicago School of Professional Psychology, Chicago, IL, USA 
disparities. We encourage you to bring your compassion, your openness to discourse, and your willingness to stand for communities and people who are discriminated against all over the world. (Association for Contextual Behavioral Science, 2020)

Behavior science broadly should endorse this statement, but more than endorsement is required. Our overall goal must be contributing to the construction of cultures of social and environmental justice (Roose \& Mattaini, in press). In this editorial, we discuss several areas where our science has, or is actively developing, research or practice programs to contribute. Research in related disciplines also has much to offer us; forging collaborations with those disciplines, as well as with affected communities, is clearly essential.

We are by no means the first to propose plans such as these. Skinner himself was hopeful that the science of behavior could be applied to the design of culture, stating that "such an analysis will embrace the fact that [people] talk about their cultures and sometimes change them" (Skinner, 1961, p. 40). Skinner delineated how a contingency analysis at the level of a culture, community, or society could facilitate deliberate solutions to social problems, rather than leaving the design of cultures to guesswork (Skinner, 1961). Unfortunately, Skinner's optimism dwindled later in his career, as coercion evolved as a normal practice in many institutions (Skinner, 1972). To wit, Skinner (1972) concluded his seminal paper "Why Are the Behavioral Sciences Not More Effective?" with the following forewarning: "It is possible that our current aggrandizement of the individual will obscure the possibility of building a better way of life. The evolution of our democratic culture will then have taken a disastrous turn" (p. 428).

Arguably, the context of our current times may lead one to believe that the evolution of our culture has indeed taken a disastrous turn, as Skinner forecasted. Chance (2007) revised Skinner's list of obstacles standing in the way of a behavior science of culture with reference to overpopulation, racism, and, ironically, a looming and overdue pandemic. Despite these challenges, we argue that behavior scientists today have the tools to analyze the context that sustains such problems. We can look to Chance for behavior-analytic explanations for social injustice stemming from racial prejudice: First, Chance states that "simple ideas that are wrong are often preferred over complex, alien ideas that are correct" (p. 155). Second, Chance acknowledges that "the use of aversives tends to be reinforcing for those who use them" (p. 156). Finally, and perhaps most alarmingly, "susceptibility to social reinforcement can incline us toward extreme views" (p. 155). Despite these challenges, Chance nonetheless calls upon the behavior science community to "prove Skinner wrong" in our application of a behavioral technology for social change.

We urge behavior scientists to align with Chance's goal. However, doing so will require us to embrace a post-Skinnerian account of language and cognition that provides a framework for understanding how interactions with the indirect functions of stimuli may supplement, and even supplant, the influence of direct-acting contingencies (see Critchfield \& Rehfeldt, 2019) in the provenance and maintenance of racism and prejudice. Dixon, Belisle, Rehfeldt, and Root (2018) explored the role of relational learning in the formation of racial prejudice and stereotypes, highlighting the "dark side" of human language. These authors describe how responding in accordance 
with vast relational networks of stimuli can result in extreme biases toward members of different racial, sexual, or religious groups. The authors provide the following example: A poor, Middle Eastern man may relate his own outrage at being poor and struggling for food with the ongoing physiological feeling of hunger, a directly experienced stimulus relation we might think of as an A-B relation. When the man overhears others in his community blaming his poverty on Americans, the directly experienced A-B relation is likely to generalize to include Americans. Through the transformation of stimulus functions (see Dymond \& Rehfeldt, 2000), the individual is likely to now experience the functions of the A and B stimuli when he encounters the word "Americans," resulting in generalized outrage toward Americans. Through similar processes, the young man may hear about the proud beliefs of a terrorist group, which promises a better tomorrow for those who align. A derived relation of opposition may emerge between "Americans" and "(name of terrorist organization), resulting in further transformations of stimulus functions: Terrorist stimuli may not only evoke further hatred for Americans, but pride, fervor, and resolution for terrorist ideas"; (Dixon et al., 2018 , p. 246). This same process may account for similar extreme prejudices and beliefs. With a relational framing repertoire intact, an individual is also likely to follow self-rules that promote behaviors that are consistent with the values of such groups (i.e., "If I join this group, I won't be hungry and Americans won't ruin our future."). Group affiliation may also be maintained by rules provided by others, which often serve an augmental, or motivational, function by appealing to people's values: Imagine, for example, the rules "My neighborhood has just always included people who are the same, and we want to continue that tradition" or "Do you really want to take a gamble on a Black hire?" Rules such as these may be closely adhered to, even when they produce dire consequences for an individual or group. Dixon et al. (2018) contend that "saving the world" with a science of behavior can only occur if a technology based on relational framing is scaled up globally.

That relational learning processes that may underlie prejudice and stereotypes has been confirmed in many laboratory studies. Weinstein, Wilson, Drake, and Kellum (2008), for example, created a laboratory model for how a culture reinforces social categorization. The authors' basic paradigm involved requiring undergraduate participants to select words that they commonly associated with "thin" and "obese." The "thin" and "obese" words were then entered into relational frames with arbitrarily configured nonsense stimuli. Participants then ascribed "thin" and "obese" meaning to the nonsense stimuli depending on their relational histories with the words that were established during the experiment. Cullen, Barnes-Holmes, Barnes-Holmes, and Stewart (2009) reported a similar process for the formation of ageist attitudes, and Cartwright, Roche, Gogarty, O'Reilly, and Stewart (2016) demonstrated similar outcomes pertaining to gender stereotypes. Similar advances have been made in the study of racial prejudice (Barnes-Holmes, Murphy, Barnes-Holmes, \& Stewart, 2010; Drake et al., 2015). A cautionary note: the extent to which violent police action toward Black people is the direct result of personal bias alone has been questioned (e.g., Cesario, Johnson, \& Terrill, 2019). Overall conditions of community bias and marginalization producing disparities in socioeconomic, educational, health, and other institutional factors have a significant impact on crime rates and public presence, producing differential rates of potentially violent police contacts. Changes in ecological conditions experienced by marginalized groups must also, then, be a focus of scientific attention. 


\section{Race and Police Violence}

Racialized injustice is not limited to violence by police, but that violence has had profound impacts on people of color since the formalization of urban policing in the mid-1800s. In northern states, the primary role of police was to "prevent disorder"generally to exercise coercive control over immigrant and free Black populations (Potter, 2013). In southern states, formal policing began with "slave patrols," offering organized terror as necessary to control Black populations and to pursue runaway slaves. Aggressive policing was initiated, and continues to be structured to support coercive functions, despite growing evidence that coercion establishes aversive motivative operations that carry heavy costs, including exacerbating conflicts between groups (Delprato, 1995; Goltz, 2020; Lewon, Houmanfar, \& Hayes, 2019; Sidman, 2002). As discussed later, contemporary cultures, including those shaped and sustained among police, but also among multiple community systems that support them, have historically shared relational framing that supports coercive individual and collective action directed toward populations of color and especially Black men, who are often collectively framed as dangerous, different from self, and in other ways undesirable. Such profoundly unjust and dangerous shared biases make aversive and coercive responses probable under a range of conditions, as has been widely documented, resulting in contemporary protests and social movements.

There are a wide range of ways to limit freedom and produce aversive conditions resulting from such actions, some of which are not immediately obvious (de Fernandes \& Dittrich, 2018). Violent policing contributes to community fragmentation (Gomez, 2016), and police killings have widespread adverse effects on Black adults in the impacted communities (Bor, Venkataramani, Williams, \& Tsai, 2018). Proactive policing, in which particular areas or persons (often youth) are targeted with the intent of social control, can in some cases reduce immediate crime, but the research of Del Toro et al. (2019), among others, confirmed serious immediate and long-term costs associated with police stops of young men of color, including more frequent criminal behavior up to 18 months later regardless of prior delinquency, as well as reduced psychological well-being.

\section{Spreading Our Wings}

\section{Supporting Changes in Police Culture}

Although the importance of individual relational responding and stereotypes are clearly central to shifting behavior, "police culture" has become a frequent focus of political rhetoric and scientific research, especially following incidents of police violence, particularly but not exclusively directed toward African Americans, for the past two decades. Consistent with Skinner's attention to the analysis and design of culture (1961, 1971, 1981, 1984), and recent work emphasizing cultural systems analysis, it is clear that a focus only on individual behaviors and the conditions supporting them is too narrow to address systemic racialized violence. Violence by police is embedded in, and in constant interaction with, a broad range of other systems that also practice, support, and reinforce racialized oppression, including police unions, politicians, and 
governments, as well as powerful persons and systems that constitute the broader economy. Violent behavior by police is largely the result of widespread matrices of both direct contingencies and relational responding. (To edit a classic Skinner quote for relational reasons, the [subject] is always right.) Racialized police violence and other forms of racialized oppression are morally wrong by widespread standards, but those behaviors are shaped and sustained by the ecological context, which must be the focus of constructing justice.

Current structures place substantial burdens on police, which should also be recognized in the search for solutions. Stressors experienced "on the job" often include

work schedules includ[ing] shiftwork, long-work hours, overtime work, and second job; traumatic events includ[ing] exposure to dead bodies, witnessing police suicide/homicide, violent confrontations, situations of abuse, riot control, seeing battered or dead children, serious accidents and hostages, failed resuscitation attempts, and assistance in disasters; organizational stressors includ[ing] lack of supervisor and/or co-workers support, job strain, effort-reward imbalance, lack of supervisor feedback, workplace discrimination, excessive paperwork, lack of recognition, [and] dealing with the public. (Violanti et al., 2017, footnote, Table 1)

Attention to reducing and managing such stressors, which increase the aversive conditions within which many police operate, deserves serious attention (Burke, 2016). In addition, street officers are in many localities dispatched for emergencies of all kinds. Police officers are typically not or poorly trained to handle some of those calls (e.g., those related to mental illness, family or neighbor disputes, homeless persons, or groups of marginalized young people with few options). Professionals with appropriate training, or those that can be cultivated from existing community groups and members, are often better choices in such cases, and shifts in that direction are among proposals currently being examined across the United States.

A good deal of research has been undertaken into "traditional police culture" (TPC; Silver, Roche, Bilach, \& Bontrager Ryon), which researchers describe as "a set of attitudes and values that assist officers in coping with the strains inherent to police work, and which provide officers a lens (or a worldview) for interpreting the world in which they work," (p. 2). In looking at "attitudes and values," we find ourselves in the realm of relational framing at a collective level. Criminologists Ingram, Terrill, and Paoline (2018) describe police culture as a collective concept, best explored through measures within work groups as they operate within organizational and community settings. The data from this study are best interpreted in terms of relational responding and cultural systems analysis (Mattaini, in press). The differing verbal communities within city governments under pressure and police unions, and between police academies and patrol conditions with veteran officers, have a profound impact on the relational framing and thereby the behavior of officers. Under these conditions, policy changes are inadequate. J. Scott Thomson, the chief of police in Camden, New Jersey, from 2008 to 2019, noted that "within a police department, culture eats policy for breakfast" (Bazelon, 2020). Science suggests that achieving real change in policing will require alternative interventions, including both shifts in relational responding as is possible through acceptance and commitment training (ACT) and alternative ecological 
exposures, in some cases requiring replacement institutions in which such shifts can be embedded, to reduce the use of force and encourage procedural justice practices, critical areas as discussed by Silver, Roche, Bilach, and Bontrager Ryon (2017).

Efforts to shift TPC have largely been concentrated in police training, only some of which has been empirically grounded (Zhang, 2015). Much of the training in inherent bias, for example, has not been rigorously examined, and some, unfortunately, has been largely lecture and test in format. ACT and some forms of behavioral skills training are much more promising (Matsuda, Garcia, Catagnus, \& Brandt, 2020), but much more research conducted in actual police settings is necessary for further advancement (e.g., O’Neill et al., 2019). Alternative policing structures, alternative community justice structures, and constructive non-cooperation are promising approaches for affecting the ecological settings of police work in ways that training and policy changes alone cannot, and deserve focused research attention.

\section{The Community Interface}

Communities are interconnected, interacting, and overlapping networks of cultural systems (Mattaini, in press). Changes in individual behavior, and in the expression of cultural practices, therefore need to be understood in ecological terms (Mattaini, 2019). Extensive research into community dynamics has been carried out for well over a century by sociologists, urban planners, social workers, and public health professionals, among others (e.g., Addams, 2010; Brady \& Burton, 2016; Du Bois, 1899; Hick, Peters, Corner, \& London, 2010). Robert Sampson and his colleagues have made enormous contributions in these areas; one recent article (O’Brien \& Sampson, 2015) is a valuable example in the area of communities and policing. Although the "broken windows" (proactive) model, in which police and other officials addressed every violation established an expectation that doing so would reduce crime and public disorder (the "public cues" theory), their findings rather "support a social escalation model where future disorder and crime emerge not from public cues but from private disorder within the community" (abstract, n.p.). These results support alternative policing models.

\section{Community Alternatives for Policing}

Many large cities have experimented with "community policing" over the past three decades as a way to both reduce crime and more successfully engage citizens in a common effort. Despite how promising this sounds, it is now widely recognized that community policing has been generally unsuccessful. Initially positive effects found by Lombardo and Donner (2018) were accounted for primarily by the level of community disorganization and the existing level of satisfaction of community members with the police. Gill, Weisburd, Telep, Vitter, and Bennett (2014) found that community policing increased citizen satisfaction and ratings of disorder but did not reduce crime or fear of crime. Rinehart Kochel and Gau (2019), in a study of 71 high-crime areas, found that the tactics police use and how those strategies are interpreted by residents can facilitate social cohesion and informal social control; the challenge, however, is having an impact on tactics and residents' interpretations. A study by Boettke, Lemke, and Palagashvili (2016) found that these efforts have been generally ineffective and 
unsustainable, due largely to "the prioritization of federal over community initiatives, the militarization of domestic police, and the erosion of genuine community-police partnerships" (p. 305). In other words, very little actual community policing occurred in the large cities studied. Contemporary expansions of the use of tactical uniforms and gear and largely black vehicles with darkened windows are more in line with the "warrior" movement in policing than with community policing (Stoughton, 2014).

As a direct effect of the 2020 homicide of George Floyd and hundreds of killings of other African Americans and other people of color, many communities began exploring alternatives to traditional policing. A particularly important example is the Camden, New Jersey, model in which the corrupt and violent city police department was eliminated, with a new, differently organized county police department taking over responsibility for the city, with an emphasis on community engagement (e.g., having coffee with community members for exchange and relationship building) and the implementation of procedural justice procedures (Doubek, 2020). This strategic change, along with a state-supported package of community development projects, reduced the homicide rate by $50 \%$, a hopeful finding.

The research of Sharkey, Torrats-Espinosa, and Takyar (2017) across 264 cities over 20 years indicated that the development and support of local nonprofit organizations that focused on reducing violence and improving community collaboration could produce significant reductions in crime, estimating that

every 10 additional organizations focusing on crime and community life in a city with 100,000 residents leads to a 9 percent reduction in the murder rate, a 6 percent reduction in the violent crime rate, and a 4 percent reduction in the property crime rate. (p. 1214)

This is an important finding, as it indicates that communities can influence crime rates and resident satisfaction independently. The authors suggest that

as the practice of aggressive or violent policing and the expansion of the criminal justice system have met with growing protest, community-based organizations may become increasingly central to the effort to control violence within communities that are vulnerable to a rise in violent crime. (p. 1236)

This is an important possibility consistent with an ecological systems perspective that deserves attention.

Behavior science can provide tools for determining what sectors within a community may contribute to achieving particular goals in integrated ways. Biglan (1995), for example, developed a matrix chart that identifies interlocking practices among community sectors that could either support or oppose sexual coercion, including networks of contingencies and metacontingencies that would influence the rates of those practices. Building on Biglan's model, Mattaini (2013) developed a data-grounded chart, further expanded in Roose and Mattaini (in press), exploring practices across community sectors that could reduce violence among young people, in part by offering participation in activism as an alternative (such participation is well supported by historical data; Stephan \& Thompson, 2018). 


\section{Accompaniment and Strategic Nonviolent Action}

Accompaniment has been defined as an approach to activism that can contribute to systemic change of adverse conditions by "walking with clients and communities through difficult journeys . . . from beginning to end . . . being present and staying there" (Mattaini \& Holtschneider, 2016, pp. 268-269). The concept has been discussed in depth by Paul Farmer, an activist physician and anthropologist who has lived out this construct in many of the most vulnerable communities in the world (Farmer, 2003, 2013). It is possible through being present to begin to identify systemic barriers to change, as well as to participate in networks of positive support (i.e., participating in networks of motivative operations and contingencies for action emerging from community values - to partner in manifestations of ACT).

Accompaniment is not simply claiming to be an "ally"-language that can in some cases be more a claim of privilege ("I am not like most of the people like me. I understand what you are going through and will help in some way."). Rather, accompaniment is to be embedded in change efforts with a long-term commitment, using whatever resources one brings to a lasting, strategic plan for social change. Being present offers opportunities to observe realities on the ground, to identify and explore significant variables to which professional training has sensitized, and to participate in (generally not to lead) planning and action in campaigns for change. The behavior scientist or practitioner brings his or her behavior science training and knowledge of cultural systems analysis to the table, whereas community members bring local knowledge, awareness of community values, and knowledge of history. If those members of diverse groups who have participated in the George Floyd protests continue by engaging with those affected in advocating for systemic change, while recognizing their own responsibility for the continuation of discrimination and systemic oppression, that is accompaniment.

Roberto Aspholm spent years working and living with marginalized young people, mostly African Americans, accompanying them through struggles and victories. In his 2020 book, Views from the Streets, Aspholm interviewed young men from the South Side of Chicago who were actively involved in street violence. His research was able to identify motivative and reinforcement factors contributing to the behaviors enacted by those men, and suggested potential data-driven constructional alternatives (Goldiamond, 1974/2002) for assisting this population to broadly engage in social action with their broader communities while researching systemic political, police, and economic barriers to doing so (see also Aspholm \& Mattaini, 2017).

Nonviolent social action is complex (Chenoweth, 2017; Chenoweth \& Stephan, 2011; Chenoweth \& Ulfelder, 2017; Sharp \& Raqib, 2010). Drawing on this work, behavior science has identified six possible strategic options for social action (Mattaini, 2013), as well as many of the relevant operant and relational variables that can contribute to success or failure for each (Chenoweth \& Stephan, 2011; Mattaini, 2013):

- persuasion: a strategy that relies on arranging reinforcement for, or shifting relational frames that increase the probability of, specific desired change by critical decision makers;

- protest: a strategy that establishes or threatens aversive events or conditions that can be relieved or avoided by taking the desired action (negative reinforcement); 
- disruptive non-cooperation: a strategy that disrupts systemic funding until desired changes occur (e.g., boycotts);

- constructive non-cooperation: a strategy that relies on constructing new community systems that essentially make current systemic arrangements irrelevant (e.g., development of collective community justice systems as alternatives to calling the police);

- resource disruption: a strategy that interferes directly with the resources for oppressive systems to function (some strikes fit in this category); and

- retaliation: a coercive and punitive strategy that is not recommended due to the high costs associated with most punishment and coercion.

The identified options can be strategically mixed and phased, and although their basic dynamics and hundreds of methods have been known for millennia (McCarthy \& Sharp, 1997; Sharp, 2005), behavioral and political sciences have offered new insights and research findings related to the behavioral and cultural dynamics underlying each strategic choice. An important note: history indicates that lasting change requires solidarity, discipline, commitment, and (generally collective) leadership - all of which have roots in relational responding.

\section{Public Policy Advocacy}

Cultural change often requires advocacy directed toward policy makers and funders; the extensive research necessary to pursue the questions raised here as essential to constructing socially and environmentally just societies requires adequate funding. Effective policy advocacy, grounded in prosocial values and ethics, is commonly discussed in terms of four phases: (a) agenda formation, (b) policy adoption, (c) policy implementation, and (d) policy review (Fawcett et al., 1988). Three of these phases (a, c, and d) have been extensively studied; there is actually very little rigorous research describing how to successfully promote policy adoption - at least in those terms (Mattaini et al., in press). There is considerable potential guidance in historical records, but most of that involves quite idiosyncratic interactions that rely on individual repertoires (e.g., a combination of "empathy" and "confidence"), values (relational frames), and personal experiences. Mattaini et al. (in press) provide a summary of what is known, suggest tools for operationalizing effective advocacy, and bring a scientific perspective on potential action.

One well-established principle is that, to achieve genuine change, the "ask" must be specific. Asking the city council to approve a statement opposing police bias toward racialized citizens, or advocating for community policing, is likely to easily receive a positive vote, but as has been made clear here, it is unlikely to produce significant change. Specificity is required; specific changes in funding consistent with specific constructional options have the potential for change at a time when adequate support from the most important community sectors can be engaged - which is nearly always essential. Once the specific behavior being advocated has been established, contextually analyzing possibilities of both energizing relevant contingencies (votes, contributions, public approval) and concurrently possibilities for shifting relational frames among key players can offer substantial guidance. Persuasion directed toward both persons in positions to make final decisions and others who have influence on the decision makers is nearly 
always critical. Both relational frame theory (Hayes, Barnes-Holmes, \& Roche, 2001) and cultural systems analysis (Mattaini, 2013) offer considerable guidance on the dynamics of persuasion for action related to social change. Some level of protest (as has currently emerged both in the United States and internationally related to police violence) also commonly functions as a powerful set of contingencies to advance social change. There is a large literature on protest available, including in Chenoweth and Stephan (2011) and Sharp and Raqib (2010). Although other strategic options are sometimes required, for most contemporary cases in somewhat democratic societies, a firm grasp of persuasive and protest approaches appears to be a useful foundation for advocacy.

\section{Conclusion}

That prejudice and stereotypes are culturally established through a person's verbal learning history should suggest a sense of renewed optimism for our field, as relational repertoires are in fact malleable and subject to change. Modifying how one interacts with the verbal functions of stimuli is in fact one of the goals of ACT. ACT is a behavioral approach to improving behavioral flexibility, or the ability to experience life as a conscious human being in spite of uncomfortable psychological experiences. ACT assumes that behavioral flexibility can be increased via instruction in six core skill components, the ultimate outcome being an individual's engagement in valuesconsistent behaviors despite unpleasant psychological experiences (Sandoz, Kellum, $\&$ Wilson, 2017). ACT has been shown to be effective in treating a host of diverse problems, including substance abuse, depression, anxiety, and distress associated with chronic health issues.

Regarding prejudice in particular, ACT assumes that stigma or prejudice is a generalized verbal process that is socioculturally influenced, often automatic, and inappropriately applied (Masuda, Hill, Morgan, \& Cohen, 2012). One of ACT's core processes is deliteralization or defusion, which specifically involves changing the functions of verbal stimuli with which a person may interact covertly. For example, an individual might be taught to repeat the fear-provoking phrases about members of different ethnic, sexual, or religious groups in various ways to alter the functions of those stimuli. Additional components of ACT focus on identifying important values with which a person may have lost contact due to his or her entanglement with language, as well as establishing committed actions or goals that will help a person reconnect with those values. A person with racial biases may come to recognize that avoiding members of different ethnic groups is costing him or her friendships, for example. Making the acquaintance of coworkers from ethnic backgrounds different from one's own may be specified as a committed action to pivot a person closer to his or her value of friendship. A variety of studies have shown that ACT is effective in reducing stigma for various groups of people (see Matsuda et al., 2020). Biglan (2016) advocates for the application of ACT at a systems level, including in the likes of schools, employment settings, and entire communities. Biglan (2016) suggests that such culture-wide interventions may produce long-term benefits for the well-being of a society, including the enhanced physical and psychological well-being of all of its members. For ACT to live up to Biglan's expectations, however, functional 
relationships between ACT and objective and reliable measures of meaningful behavior change are needed.

ACT for culture-wide change resonates with the recent upsurge of interest in evolutionary science among contextual behavior scientists. Skinner (1981) affirmed that human behavior is the joint product of the contingencies of survival responsible for natural selection and the contingencies of reinforcement responsible for the repertoires of individuals, including contingencies sustained by an evolved social environment. This multilevel selectionist account has enabled evolutionary scientists to account for the evolution of altruism and prosocial behavior among members of a community (Sloan-Wilson, 2014). Sloan-Wilson suggests that how individuals in groups behave toward one another can have a long-lasting impact on the health, longevity, and survival of a society. Sloan-Wilson (2011) narrated evidence for this in his compelling case study of Binghamton, New York, where the concepts of evolutionary science were applied in multiple ways to improve the quality of life for its residents. In doing this work, it is important to recognize that changes among multiple community sectors are not simply additive; change in one system will often produce changes in others, desirable or otherwise. For example, as discussed previously, self-organized autopoietic processes within police unions are likely to produce changes in police behavior on the street, emerging from relational processes supporting bias within that system external to police training and administration. Cultural analytic science (Mattaini, in press) offers tools to identify and analyze the dynamics of such interactions, as well as to construct alternative models at the cultural level for testing.

Behavior analysts would do well to look to our leaders in the biological sciences to explore, from a selectionist perspective, how racism, bigotry, and hatred are compromising lives and threatening the very core of humankind. The time is ripe for the extension of the thoroughgoing science that Skinner envisioned to widespread cultural change. A society of nurturance and compassion, that celebrates and promotes love for the uniqueness and inherent value of all humans, is long overdue (Biglan, 2015). Behavior science has the framework to meet the challenges of 2020 head-on. The time for intentional change is now.

\section{Compliance with Ethical Standards}

Conflict of Interest We have no known conflicts of interest to disclose.

\section{References}

Addams, J. (2010). The spirit of youth and the city streets. Champaign, IL: University of Illinois Press.

Aspholm, R. R. (2020). Views from the streets: The transformation of gangs and violence on Chicago's South Side. New York, NY: Columbia University Press.

Aspholm, R. R., \& Mattaini, M. A. (2017). Youth activism as violence prevention. In P. Sturmey (Ed.), The Wiley handbook of violence and aggression (pp. 1-12). Hoboken, NJ. Wiley. https://doi.org/10.1002 /9781119057574.whbva104

Association for Contextual Behavioral Science. (2020). ACBS statement on racism and violence. Retrieved from https://contextualscience.org/news/acbs_statement_on_racism_and_violence

Barnes-Holmes, D., Murphy, A., Barnes-Holmes, Y., \& Stewart, I. (2010). The implicit relational assessment procedure: Exploring the impact of private versus public contexts and the response latency criterion on 
pro-White and anti-Black stereotyping among White Irish individuals. The Psychological Record, 60(1), 57-79. https://doi.org/10.1007/BF03395694.

Bazelon, E. (Moderator). (2020). Police reform is necessary. But how do we do it? The New York Times. https://www.nytimes.com/interactive/2020/06/13/magazine/police-reform.html

Biglan, A. (1995). Changing cultural practices. Oakland, CA: Context Press.

Biglan, A. (2015). The nurture effect: How the science of human behavior can improve our lives and our world. Oakland, CA: New Harbinger Publications.

Biglan, A. (2016). The need for a more effective science of cultural practices. The Behavior Analyst, 39(1), 97-107. https://doi.org/10.1007/s40614-016-0051-z.

Boettke, P. J., Lemke, J. S., \& Palagashvili, L. (2016). Re-evaluating community policing in a polycentric system. Journal of Institutional Economics, 12(2), 305-325. https://doi.org/10.2139/ssrn.2635646.

Bor, J., Venkataramani, A. S., Williams, D. R., \& Tsai, A. C. (2018). Police killings and their spillover effects on the mental health of Black Americans: A population-based, quasi-experimental study. The Lancet, 392(10144), 302-310. https://doi.org/10.1016/S0140-6736(18)31130-9.

Brady, D., \& Burton, L. M. (Eds.). (2016). The Oxford handbook of the social science of poverty. New York, NY: Oxford University Press.

Burke, R. J. (2016). Stress in policing: Sources, consequences and interventions. Oxford, UK: Routledge.

Cartwright, A., Roche, B., Gogarty, M., O’Reilly, A., \& Stewart, I. (2016). Using a modified Function Acquisition Speed Test (FAST) for assessing implicit gender stereotypes. The Psychological Record, 66(2), 223-233. https://doi.org/10.1007/s40732-016-0164-5.

Cesario, J., Johnson, D. J., \& Terrill, W. (2019). Is there evidence of racial disparity in police use of deadly force? Analyses of officer-involved fatal shootings in 2015-2016. Social Psychological and Personality Science, 10(5), 586-595. https://doi.org/10.1177/1948550618775108.

Chance, P. (2007). The ultimate challenge: Prove B. F. Skinner wrong. The Behavior Analyst, 30, $153-160$. https://doi.org/10.1007/BF03392152.

Chenoweth, E. (2017). Democracy as a method of nonviolence. In N. P. Gleditsch (Ed.), R. J. Rummel: An assessment of his many contributions (pp. 107-115). Cham, Switzerland: Springer.

Chenoweth, E., \& Stephan, M. (2011). Why civil resistance works. New York, NY: Columbia University Press.

Chenoweth, E., \& Ulfelder, J. (2017). Can structural conditions explain the onset of nonviolent uprisings? Journal of Conflict Resolution, 61(2), 298-324. https://doi.org/10.1177/0022002715576574.

Critchfield, T. S., \& Rehfeldt, R. A. (2019). Engineering emergent learning with nonequivalence relations. In J. O. Cooper, T. E. Heron, \& W. L. Heward (Eds.), Applied behavior analysis (3rd ed., pp. 497-526). New York: Pearson.

Cullen, C., Barnes-Holmes, D., Barnes-Holmes, Y., \& Stewart, I. (2009). The implicit relational assessment procedure (IRAP) and the malleability of ageist attitudes. The Psychological Record, 59(4), 591-620. https://doi.org/10.1007/BF03395683.

de Fernandes, R. C., \& Dittrich, A. (2018). Expanding the behavior-analytic meanings of "freedom": The contributions of Israel Goldiamond. Behavior and Social Issues, 27(1), 4-19. https://doi.org/10.5210/bsi. v27i0.8248.

Del Toro, J., Lloyd, T., Buchanan, K. S., Robins, S. J., Bencharit, L. Z., Smiedt, M. G., et al. (2019). The criminogenic and psychological effects of police stops on adolescent Black and Latino boys. Proceedings of the National Academy of Sciences, 116(17), 8261-8268. https://doi.org/10.1073/pnas.1808976116.

Delprato, D. J. (1995). Beyond Murray Sidman's Coercion and its fallout. The Psychological Record, 45(3), 339-347. https://doi.org/10.1007/bf03395146.

Dixon, M. R., Belisle, J., Rehfeldt, R. A., \& Root, W. B. (2018). Why we are still not acting to save the world: The upward challenge of a post-Skinnerian behavior science. Perspectives on Behavior Science, 41(1), 241-267. https://doi.org/10.1007/s40614-018-0162-9.

Doubek, J. (2020). Former chief of reformed Camden, N.J., force: Police need "consent of the people." Retrieved from https://www.npr.org/sections/live-updates-protests-for-racial-justice/2020/06/08 /872416644/former-chief-of-reformed-camden-n-j-force-police-need-consent-of-the-people

Drake, C. E., Kramer, S., Sain, T., Swiatek, R., Kohn, K., \& Murphy, M. (2015). Exploring the reliability and convergent validity of implicit racial evaluations. Behavior and Social Issues, 24(1), 68-87. https://doi. org/10.5210/bsi.v24i0.5496.

Du Bois, W. E. B. (1899). The Philadelphia negro. Philadelphia, PA: University of Philadelphia Press.

Dymond, S., \& Rehfeldt, R. A. (2000). Understanding complex behavior: The transformation of stimulus functions. The Behavior Analyst, 23, 239-254. https://doi.org/10.1007/bf03392013.

Farmer, P. (2003). Pathologies of power. Berkeley: University of California Press.

Farmer, P. (2013). To repair the world. Berkeley: University of California Press. 
Fawcett, S. B., Bernstein, G. S., Czyzewski, M. J., Greene, B. F., Hannah, G. T., Iwata, B. A., et al. (1988). Recommendations of the Task Force on Public Policy. The Behavior Analyst, 11(1), 27-32. https://doi. org/10.1007/BF03392451.

Gill, C., Weisburd, D., Telep, C. W., Vitter, Z., \& Bennett, T. (2014). Community-oriented policing to reduce crime, disorder and fear and increase satisfaction and legitimacy among citizens: A systematic review. Journal of Experimental Criminology, 10(4), 399-428. https://doi.org/10.1007/s11292-014-9210-y.

Goldiamond, I. (2002). Toward a constructional approach to social problems: Ethical and constitutional issues raised by applied behavior analysis. Behavior and Social Issues, 11, 108-197. https://doi.org/10.5210/bsi. v11i2.92 (Original work published 1974).

Goltz, S. M. (2020). On power and freedom: Extending the definition of coercion. APA PsycNet Direct. https://doi.org/10.1037/e509002019-001.

Gomez, M. B. (2016). Policing, community fragmentation, and public health: Observations from Baltimore. Journal of Urban Health, 93(1), 154-167. https://doi.org/10.1007/s11524-015-0022-9.

Hayes, S. C., Barnes-Holmes, D., \& Roche, B. (2001). Relational frame theory: A post-Skinnerian account of human language and cognition. New York, NY: Kluwer Academic/Plenum.

Hick, S. F., Peters, H. I., Corner, T., \& London, T. (2010). Structural social work in action. Toronto, Ontario, Canada: Canadian Scholars Press.

Ingram, J. R., Terrill, W., \& Paoline III, E. A. (2018). Police culture and officer behavior: Application of a multilevel framework. Criminology, 56(4), 780-811. https://doi.org/10.1111/1745-9125.12192.

King Jr., M. L. (1968). The role of the behavioral scientist in the civil rights movement. American Psychologist, 23(3), 180-186. https://doi.org/10.1037/h0025715.

Lewon, M., Houmanfar, R. A., \& Hayes, L. J. (2019). The will to fight: Aversion-induced aggression and the role of motivation in intergroup conflicts. Perspectives on Behavior Science, 42, 889-910. https://doi. org/10.1007/s40614-019-00221-2.

Lombardo, R. M., \& Donner, C. M. (2018). Can community policing increase residents' informal social control? Testing the impact of the Chicago Alternative Policing Strategy. Police Practice and Research, 19(5), 427-442. https://doi.org/10.1080/15614263.2017.1405265.

Masuda, A., Hill, M. L., Morgan, J., \& Cohen, L. L. (2012). A psychological flexibility-based intervention for modulating the impact of stigma and prejudice: A descriptive review of empirical evidence. Psychology, Society, \& Education, 4(2), 211-223. https://doi.org/10.25115/psye.v4i2.492.

Matsuda, K., Garcia, Y., Catagnus, R., \& Brandt, J. A. (2020). Can behavior analysis help us understand and reduce racism? A review of the current literature. Behavior Analysis in Practice. https://doi.org/10.1007 /s40617-020-00411-4.

Mattaini, M. A. (2013). Strategic nonviolent power: The science of satyagraha. Edmonton, Alberta, Canada: Athabasca University Press.

Mattaini, M. A. (2019). Out of the lab: Shaping an ecological and constructional cultural systems science. Perspectives on Behavior Science, 42, 713-731. https://doi.org/10.1007/s40614-019-00208-z.

Mattaini, M. A. (in press). Cultural systems analysis: An emerging science. In T. Cihon \& M. A. Mattaini (Eds.), Behavioral perspectives on culture and community. Cham, Switzerland: Springer.

Mattaini, M. A., Esquierdo-Leal, J. L., Ardila Sánchez, J. G., Richling, S. M., \& Ethridge, A. N. (in press). Public policy advocacy in culturo-behavior science. In T. Cihon \& M. A. Mattaini (Eds.), Behavioral perspectives on culture and community. Cham, Switzerland: Springer.

Mattaini, M. A., \& Holtschneider, C. (2016). Foundations of social work practice. Washington, DC: NASW Press.

McCarthy, R. M., \& Sharp, G. (1997). Nonviolent action. New York, NY: Garland Publishing.

O'Brien, D. T., \& Sampson, R. J. (2015). Public and private spheres of neighborhood disorder: Assessing pathways to violence using large-scale digital records. Journal of Research in Crime and Delinquency, 52(4), 486-510. https://doi.org/10.1177/0022427815577835.

O’Neill, J., O’Neill, D. A., Weed, K., Hartman, M. E., Spence, W., \& Lewinski, W. J. (2019). Police academy training, performance, and learning. Behavior Analysis in Practice, 12(2), 353-372. https://doi. org/10.1037/e511592010-006.

Potter, G. (2013). The history of policing in the United States. Retrieved from https://plsonline.eku. edu/sites/plsonline.eku.edu/files/the-history-of-policing-in-us.pdf

Rinehart Kochel, T., \& Gau, J. M. (2019). Examining police presence, tactics, and engagement as facilitators of informal social control in high-crime areas. Justice Quarterly. Advance online publication. https://doi. org/10.1080/07418825.2019.1632917.

Roose, K. M., \& Mattaini, M. A. (in press). Challenging violence: Toward a 21 st century, science-based constructive programme. In T. Cihon \& M. A. Mattaini (Eds.), Behavioral perspectives on culture and community. Cham, Switzerland: Springer. 
Sandoz, E. K., Kellum, K. K., \& Wilson, K. G. (2017). Feasibility and preliminary effectiveness of acceptance and commitment training for academic success of at-risk college students from low income families. Journal of Contextual Behavioral Science, 6(1), 71-79. https://doi.org/10.1016/j.jcbs.2017.01.001.

Sharkey, P., Torrats-Espinosa, G., \& Takyar, D. (2017). Community and the crime decline: The causal effect of local nonprofits on violent crime. American Sociological Review, 82(6), 1214-1240. https://doi. org/10.1177/0003122417736289.

Sharp, G. (2005). Waging nonviolent struggle: 20th century practice and 21st century potential. Manchester, NH: Extending Horizons Books.

Sharp, G., \& Raqib, J. (2010). Self-liberation: A guide to strategic planning for action to end a dictatorship or other oppression. Boston, MA: Albert Einstein Institution.

Sidman, M. (2002). Coercion and its fallout (rev. ed.). Boston, MA: Authors Cooperative.

Silver, J. R., Roche, S. P., Bilach, T. J., \& Bontrager Ryon, S. (2017). Traditional police culture, use of force, and procedural justice: Investigating individual, organizational, and contextual factors. Justice Quarterly, 34(7), 1272-1309. https://doi.org/10.1080/07418825.2017.1381756.

Skinner, B. F. (1961). The design of cultures. Daedalus, 90, 534-546. https://doi.org/10.5210/bsi.v11i1.97.

Skinner, B. F. (1972). Why are the behavioral sciences not more effective? In B. F. Skinner, Cumulative Record (pp. 421-428). New York: Appleton-Century-Crofts.

Skinner, B. F. (1981). Selection by consequences. Science, 213, 501-504. https://doi.org/10.1126 /science. 7244649 .

Skinner, B. F. (1984). The evolution of culture. Journal of the Experimental Analysis of Behavior, 41, 217221. https://doi.org/10.1901/jeab.1984.41-217.

Stephan, M. J., \& Thompson, T. P. (2018). Why you should never underestimate a bunch of well-organized teenage protesters. The Washington Post. Retrieved from https://www.washingtonpost. com/news/democracy-post/wp/2018/04/04/why-you-should-never-underestimate-a-bunch-of-wellorganized-teenage-protesters/?noredirect=on

Stoughton, S. (2014). Law enforcement's “warrior" problem. Harvard Law Review Forum, Policing, 128, 225-234.

Violanti, J. M., Charles, L. E., McCanlies, E., Hartley, T. A., Baughman, P., Andrew, M. E., et al. (2017). Police stressors and health: A state-of-the-art review. Policing: An International Journal of Police Strategies \& Management, 40(4), 642-656. https://doi.org/10.1108/PIJPSM-06-2016-0097.

Weinstein, J. H., Wilson, K. G., Drake, C. E., \& Kellum, K. K. (2008). A relational frame theory contribution to social categorization. Behavior and Social Issues, 17(1), 40-65. https://doi.org/10.5210/bsi.v17i1.406.

Wilson, D. S. (2011). The Neighborhood Project: Using evolution to improve my city, one block at a time. Boston, MA: Little, Brown.

Wilson, D. S. (2014). Does altruism exist? Culture, genes, and the welfare of others. New Haven, CT: Yale University Press.

Zhang, S. (2015). Police training is seriously lacking in actual science. Wired. Retrieved from https://www. wired.com/2015/08/police-training-seriously-lacking-actual-science/?mbid=email_onsiteshare 